\title{
Study on the pathogenesis of liver injury caused by alcohol and drugs
}

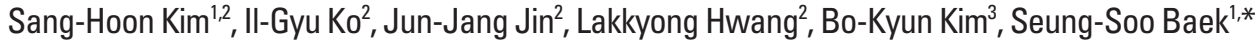 \\ 'Department of Sport \& Health Sciences, College of Art \& Culture, Sangmyung University, Seoul, Korea \\ ${ }^{2}$ Department of Physiology, College of Medicine, Kyung Hee University, Seoul, Korea \\ ${ }^{3}$ Department of Emergency Technology, College of Health Science, Gachon University, Incheon, Korea
}

In the present study, alcohol, lipopolysaccharide (LPS), and carbon tetrachloride (CCL) were administered to experimental mice. Alanine aminotransferase (ALT) and aspartate aminotransferase (AST) levels, tumor necrosis factor (TNF)- $\alpha$, interleukin (IL)-1 $\beta$, and IL-6 concentrations, and collagen type 1alpha (COL-1A) and fibronectin expressions were measured to evaluate pathophysiology of liver injury. Levels of ALT and AST were significantly increased by alcohol treatment. Alcohol with LPS treatment increased ALT and AST levels more than alcohol alone treatment, but it was not statistically significant. Alcohol with CCL4 treatment significantly increased ALT and AST levels more than alcohol alone treatment. Alcohol with LPS and CCL4 treatment significantly increased ALT and AST levels more than alcohol with CCL treatment. Concentrations of TNF- $\alpha$, IL-1 $\beta$, and IL- 6 were significantly enhanced by alcohol treatment. Alcohol with LPS treatment significantly enhanced concentrations of TNF- $\alpha$, IL-1 $\beta$, and IL- 6 more than alcohol alone treatment. Al- cohol with CCL treatment significantly enhanced TNF- $\alpha$, IL-1 $\beta$, and IL-6 concentrations more than alcohol alone treatment. Alcohol with LPS and $\mathrm{CCL}_{4}$ treatment increased TNF- $\alpha$, IL-1 $\beta$, and IL- 6 concentrations more than alcohol with CCL4 treatment, but it was not statistically significant. COL-1A and fibronectin expressions were significantly increased by alcohol treatment. Alcohol with LPS treatment significantly increased COL-1A and fibronectin expressions more than alcohol alone treatment. Alcohol with CCL4 treatment significantly increased COL-1A and fibronectin expressions more than alcohol alone treatment. Alcohol with LPS and CCL4 treatment increased COL-1A and fibronectin expressions more than alcohol with CCLa treatment, but it was not statistically significant.

Keywords: Liver injury, Alcohol, Lipopolysaccharide, CCL

\section{INTRODUCTION}

The liver is an important organ, responsible for many physiological functions, including metabolism. But, alcohol, drugs, chemicals, and infections induce liver toxicity and eventually cause liver injury (Tsai et al., 2017; Zhang et al., 2017). Acute liver injury causes several clinical problems, such as blood clotting disorders, hepatic encephalopathy, and high mortality (Bernal et al., 2010; Lee et al., 2012). Alcoholic liver disease is difficult to cure, and the biggest problem is that when cirrhosis progresses, there is no treatment method except organ transplantation. In alcoholic cirrhosis, the mortality rate is 5 to 30 times higher than that of the general population (Fleming et al., 2012; Jepsen et al.,
2010), and the 5-year survival rate is $23 \%-50 \%$, which is higher than that of nonalcoholic cirrhosis (Diehl, 2002).

Lipopolysaccharide (LPS) is found in the outer membrane of Gram-negative bacteria, and the term endotoxin is mostly used synonymously with LPS (Rietschel et al., 1994). Intratracheal administration of LPS is used to induce acute lung injury animal model (Xie et al., 2012). Intratracheal instillation of LPS, expressions of proinflammatory cytokines in bronchoalveolar lavage fluid, serum, and lung tissue were rapidly increased (Ko et al., 2020a).

Carbon tetrachloride is a compound composed of carbon and chlorine, and the molecular formula is $\mathrm{CCL}_{4}$. It exists in a liquid state at room temperature, has a large molecular weight, and has no flammability but is highly toxic. Carbon tetrachloride acts as a
${ }^{*}$ Corresponding author: Seung-Soo Baek (D) https://orcid.org/0000-0002-1340-2098 Department of Sport \& Health Care, College of Art \& Culture, Sangmyung University, 20 Hongjimun 2-gil, Jongno-gu, Seoul 03016, Korea Email: ssoop@smu.ac.kr

Received: August 7, 2021 / Accepted: September 10, 2021
This is an Open Access article distributed under the terms of the Creative Commons Attribution Non-Commercial License (https://creativecommons.org/licenses/by-nc/4.0/) which permits unrestricted non-commercial use, distribution, and reproduction in any medium, provided the original work is properly cited. 
central nervous system depressant, so exposure to high concentration causes loss of consciousness. Prolonged contact with $\mathrm{CCL}_{4}$ can damage the liver, adversely affect the reproductive system and act as a mutagen to cause cancer. Liver damage leads to conditions such as hepatitis, cirrhosis, alcoholic liver disease, and liver cancer (AlSayed et al., 2014).

In this experiment, alcohol, LPS, and $\mathrm{CCL}_{4}$ were administered to experimental mice. The levels of alanine aminotransferase (ALT) and aspartate aminotransferase (AST), the concentrations of tumor necrosis factor (TNF)- $\alpha$, interleukin (IL)- $1 \beta$, and IL- 6 , and the expressions of collagen type 1alpha (COL-1A) and fibronectin were measured to evaluate pathophysiology of liver injury.

\section{MATERIALS AND METHODS}

\section{Animals and treatments}

Forty 8-week-old ICR male mice were subjected to deliberation and evaluation by the Animal Ethics Review Committee, and after certification (KHSASP-20-495), the experiment was carried out. Experimental groups were classified into control group, alcohol-treated group, alcohol and LPS-treated group, alcohol and $\mathrm{CCL}_{4}$-treated group, and alcohol and LPS with $\mathrm{CCL}_{4}$-treated group ( $n=10$ in each group). Treatment methods of alcohol and drugs are shown in Table 1.

\section{Blood sampling and determination of ALT and AST levels}

For blood collection of experimental animals, $1 \mathrm{ml}$ of blood was collected from the jugular vein using a disposable syringe, and plasma was separated by centrifugation at a speed of 3,000 rpm for $15 \mathrm{~min}$. The levels of ALT and AST were measured using an automatic blood biochemistry analyzer (Olympus, Tokyo, Japan) in the same manner as previous described method (Ko et al., 2020b).

Table 1. Methods of inducing liver disease using alcohol and drugs

\begin{tabular}{|c|c|c|}
\hline Group & Alcohol & Drugs \\
\hline Control & - & - \\
\hline Alcohol-treated & \multirow{4}{*}{$\begin{array}{l}\text { - } 0.5 \mathrm{~mL} \text { of } 50 \% \text { ethanol } \\
\text { - Twice a day for } 4 \text { wk } \\
\text { - Orally administration }\end{array}$} & - \\
\hline $\begin{array}{l}\text { Alcohol and } \\
\text { LPS-treated }\end{array}$ & & $\begin{array}{l}\text { - LPS } 1 \mathrm{~mL} / \mathrm{kg} \\
\text { - } 3 \text { times/wk/4 wk } \\
\text { - Intraperitoneal injection }\end{array}$ \\
\hline $\begin{array}{l}\text { Alcohol and } \\
\text { CCL4-treated }\end{array}$ & & $\begin{array}{l}\text { - } \mathrm{CCL}_{4} 0.6 \mathrm{~mL} / \mathrm{kg} \\
\text { - } 3 \text { times/wk/4 wk } \\
\text { - Intraperitoneal injection }\end{array}$ \\
\hline $\begin{array}{l}\text { Alcohol and LPS } \\
\text { with CCL-treated }\end{array}$ & & $\begin{array}{l}\text { - LPS } 1 \mathrm{~mL} / \mathrm{kg} \text { and } \mathrm{CCL}_{4} 0.6 \mathrm{~mL} / \mathrm{kg} \\
\text { - } 3 \text { times/wk/4 wk } \\
\text { - Intraperitoneal injection }\end{array}$ \\
\hline
\end{tabular}

LPS, lipopolysaccharide; CCL4, carbon tetrachloride.

\section{Concentrations of proinflammatory cytokines}

The concentrations of proinflammatory cytokines such as TNF- $\alpha$, IL-1 $\beta$, and IL-6 were detected by enzyme-linked immunoassay using enzyme immunoassay kit (Abcam, Cambridge, UK) in the same manner as previous described method (Ko et al., 2018; Timóteo et al., 2019).

\section{Western blot analysis}

Western blotting was conducted to determine the expressions of collagen type I and fibronectin at the protein levels in liver tissue in the same manner as previous described method (Ji et al., 2020; Kim et al., 2020). The liver tissues were homogenized on ice using a homogenizer, and the supernatants were collected by centrifugation after dissolving the tissues in lysis buffer. The collected supernatants were quantified using the Bradford assay kit (Bio-Rad, Hercules, CA, USA). After electrophoresis of $40-\mu \mathrm{g}$ protein on
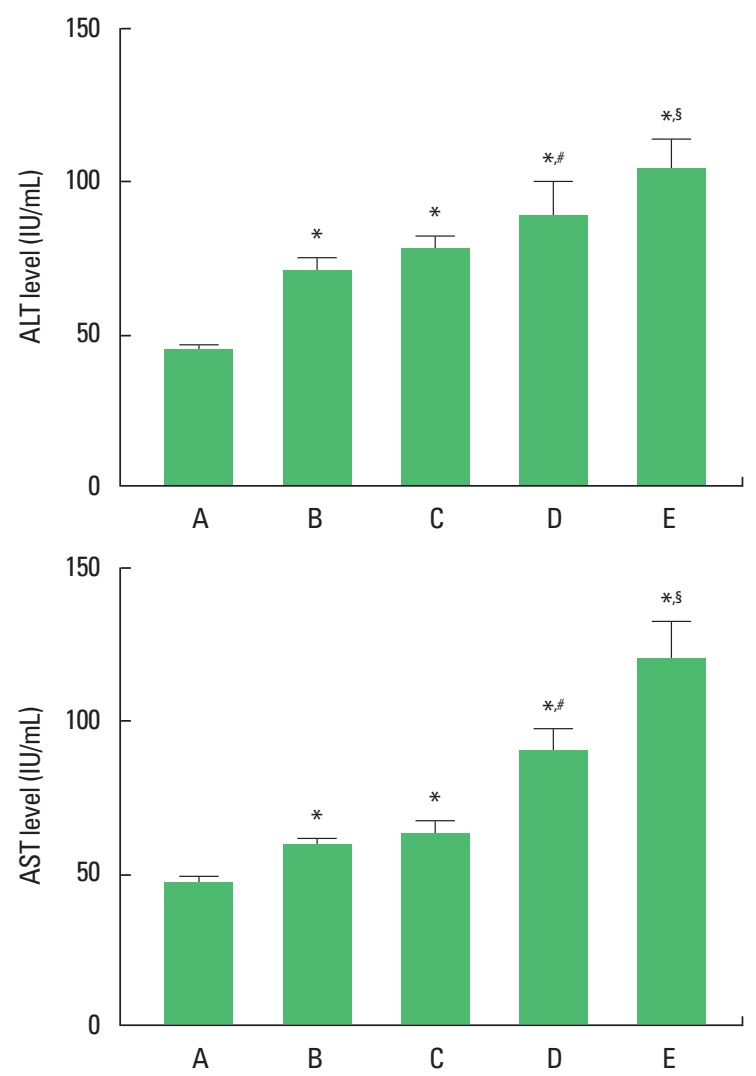

Fig. 1. The levels of alanine aminotransferase (ALT) and aspartate aminotransferase (AST). Upper panel: ALT level. Lower panel: AST level. A, control group; $\mathrm{B}$, alcohol-treated group, $\mathrm{C}$, alcohol and lipopolysaccharide (LPS)-treated group; D, alcohol and CCL-treated group; E, alcohol and LPS with CCL-treated group. ${ }^{*} P<0.05$ compared to control group. ${ }^{*} P<0.05$ compared to the alcohol and LPS-treated group. ${ }^{\S} P<0.05$ compared to the alcohol and $\mathrm{CCL}_{4}$-treated group. $\mathrm{CCL}_{4}$, carbon tetrachloride. 

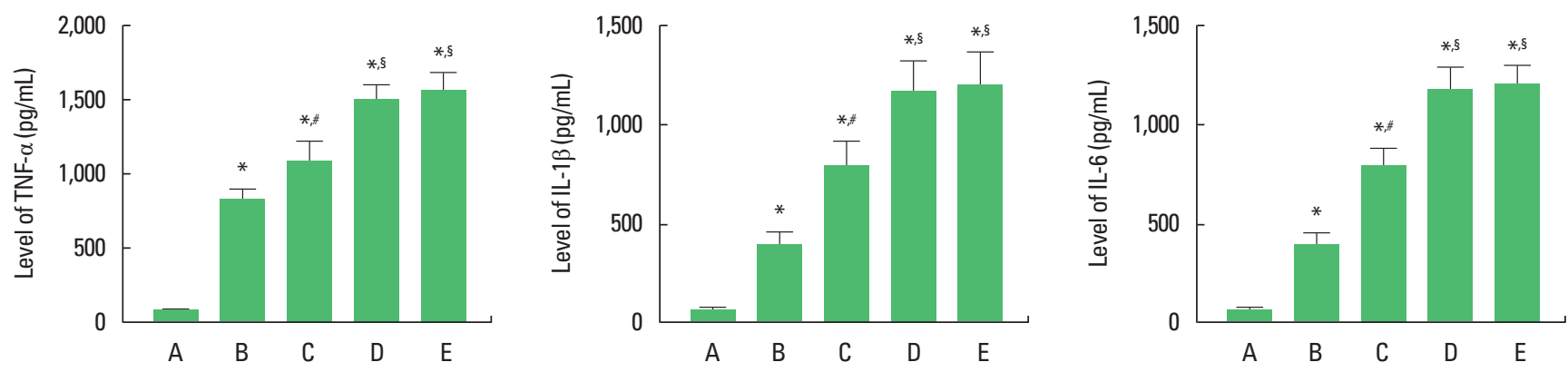

Fig. 2. The concentrations of tumor necrosis factor (TNF)- $\alpha$, interleukin (IL)-1 $\beta$, and IL-6. Left panel: TNF- $\alpha$ concentration. Middle panel: IL-1 $\beta$ concentration. Right panel: IL-6 concentration. A, control group; B, alcohol-treated group, C, alcohol and lipopolysaccharide (LPS)-treated group; D, alcohol and CCL-treated group; E, alcohol and LPS with CCL4-treated group. ${ }^{*} P<0.05$ compared to control group. ${ }^{\sharp} P<0.05$ compared to the alcohol-treated group. ${ }^{\S} P<0.05$ compared to the alcohol and LPS-treated group. CCL4, carbon tetrachloride.

$12 \%$ sodium dodecyl sulfate-polyacrylamide gel, the proteins were transferred to a nitrocellulose membrane and reacted at room temperature for $1 \mathrm{hr}$ using 4\% skin milk. Each primary antibody was incubated at $4{ }^{\circ} \mathrm{C}$ overnight and washed 3 times with tris-buffered saline and $0.05 \%$ tween 20 at 10-min intervals. Each secondary antibody was reacted at room temperature for $1 \mathrm{hr}$, then washed 3 times with $0.05 \%$ tween 20 at 15 -min intervals again. Finally, it was developed by chemiluminescence and then quantified.

\section{RESULTS}

\section{Effect of alcohol and drugs administration on AST and ALT levels}

It was confirmed that ALT and AST levels were enhanced by alcohol and drugs administration. The levels of ALT and AST were enhanced in the order of alcohol-treated group $=$ alcohol and LPStreated group $<$ alcohol and $\mathrm{CCL}_{4}$-treated group $<$ alcohol and LPS with CCL-treated group (Fig. 1).

\section{Effect of alcohol and drugs administration on concentrations of proinflammatory cytokines}

It was confirmed that proinflammatory cytokines concentrations were increased by alcohol and drugs administration. The concentrations of TNF- $\alpha$, IL- $1 \beta$, and IL- 6 were increased in the order of alcohol-treated group $<$ alcohol and LPS-treated group $<$ alcohol and $\mathrm{CCL}_{4}$-treated group $=$ alcohol and LPS with $\mathrm{CCL}_{4}$-treated group (Fig. 2).

\section{Effect of alcohol and drugs administration on expressions of fibrous factors}

It was confirmed that expressions of fibrous factors in the liver were increased by alcohol and drugs administration. The expres-

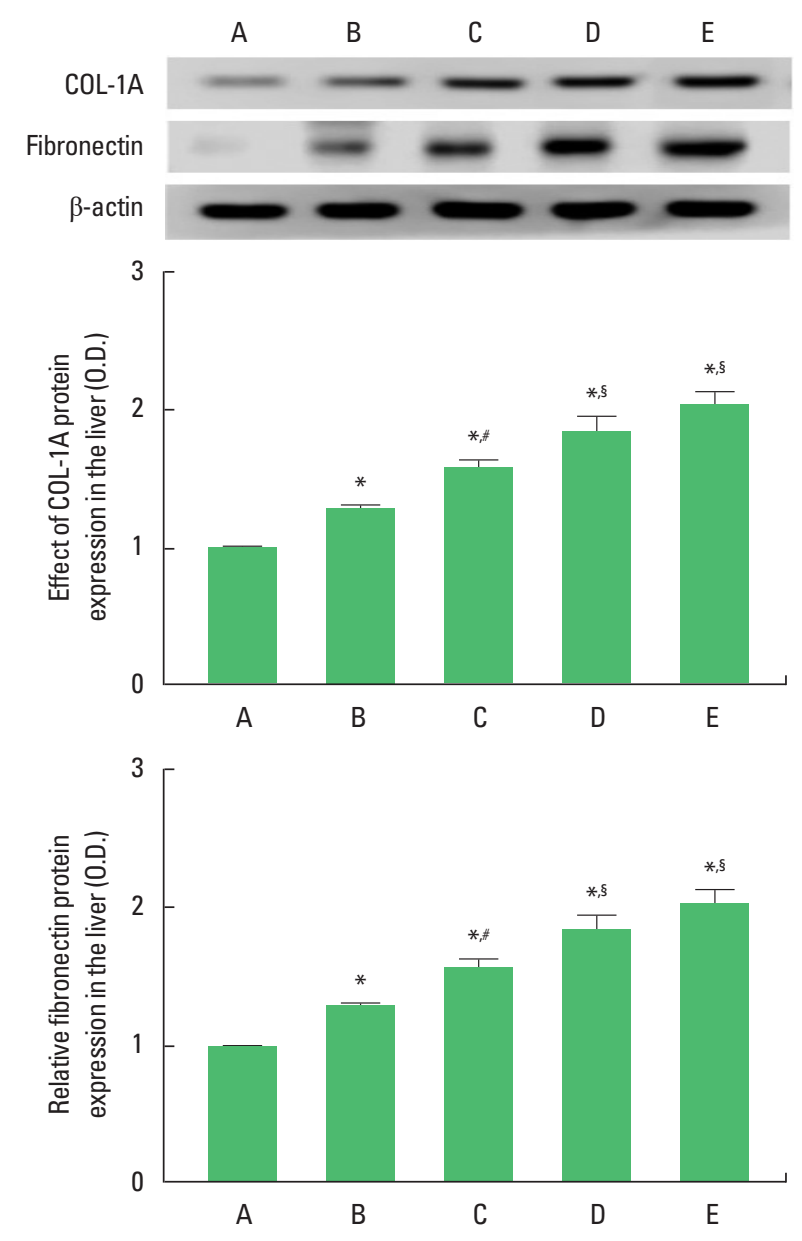

Fig. 3. The expression of collagen type 1alpha (COL-1A) and fibronectin. Upper panel: representative expression of COL-1A and fibronectin. Middle panel: relative expression of COL-1A. Lower panel: relative expression of fibronectin. $A$, control group; B, alcohol-treated group, C, alcohol and lipopolysaccharide (LPS)-treated group; D, alcohol and CCL-treated group; E, alcohol and LPS with CCL4-treated group. ${ }^{*} P<0.05$ compared to control group. ${ }^{*} P<0.05$ compared to the alcohol-treated group. ${ }^{\S} P<0.05$ compared to the alcohol and LPS-treated. $\mathrm{CCL}_{4}$, carbon tetrachloride. 
sions of COL-1A and fibronectin were increased in the order of alcohol-treated group $<$ alcohol and LPS-treated group $<$ alcohol and $\mathrm{CCL}_{4}$-treated group $=$ alcohol and LPS with $\mathrm{CCL}_{4}$-treated group (Fig. 3).

\section{DISCUSSION}

In the current results, levels of ALT and AST were significantly increased by alcohol treatment. Alcohol with LPS treatment increased ALT and AST levels more than alcohol alone treatment, but it was not statistically significant. Alcohol with $\mathrm{CCL}_{4}$ treatment significantly increased ALT and AST levels more than alcohol alone treatment. Alcohol with LPS and $\mathrm{CCL}_{4}$ treatment significantly increased ALT and AST levels more than alcohol with $\mathrm{CCL}_{4}$ treatment.

After acute alcohol exposure, concentrations of serum ALT and AST, glutamine transferase, and nitric oxide as well as hepatic malondialdehyde activity were increased (Xie et al., 2021). When $\mathrm{CCL}_{4}$ was injected intraperitoneally in rats to induce acute liver injury, ALT and AST concentrations were increased (Lee et al., 2020). $\mathrm{CCL}_{4}$ injection into mice enhanced serum levels of ALT and AST (Ko et al., 2020b).

In the current results, concentrations of TNF- $\alpha$, IL-1 $\beta$, and IL-6 were significantly enhanced by alcohol treatment. Alcohol with LPS treatment significantly enhanced concentrations of TNF- $\alpha$, IL- $1 \beta$, and IL-6 more than alcohol alone treatment. Alcohol with $\mathrm{CCL}_{4}$ treatment significantly enhanced TNF- $\alpha$, IL-1 $\beta$, and IL- 6 concentrations more than alcohol alone treatment. Alcohol with LPS and $\mathrm{CCL}_{4}$ treatment increased TNF- $\alpha$, IL-1 $\beta$, and IL-6 concentrations more than alcohol with $\mathrm{CCL}_{4}$ treatment, but it was not statistically significant.

When LPS was injected into the cerebral ventricle with a stereotaxic instrument, TNF- $\alpha$ and IL- 6 concentrations in the hippocampus were increased, showing brain inflammation (Ko and Ko, 2020). When human lung epithelial A5 49 cells were treated with LPS and transforming growth factor to create acute respiratory distress syndrome, concentrations of TNF- $\alpha$ and IL- 6 were increased (Hwang et al., 2020). Injection of $\mathrm{CCL}_{4}$ intraperitoneally to mice, expressions of TNF- $\alpha$, IL- $1 \beta$, and IL- 6 in the liver were increased, representing acute liver injury (Lee et al., 2020). Enhancement of TNF- $\alpha$ and IL- 6 concentrations was observed in Achilles tendon injury (Rho et al., 2020). CCL 4 was injected intraperitoneally to evaluate fibrotic and inflammatory signaling pathways for liver injury in rats (Morsy et al., 2021). As the results, the concentrations of AST, ALT, TNF- $\alpha$, and IL- 6 were increased (Morsy et al., 2021).

In the current results, COL-1A and fibronectin expressions were significantly increased by alcohol treatment. Alcohol with LPS treatment significantly increased COL-1A and fibronectin expressions more than alcohol alone treatment. Alcohol with $\mathrm{CCL}_{4}$ treatment significantly increased COL-1A and fibronectin expressions more than alcohol alone treatment. Alcohol with LPS and $\mathrm{CCL}_{4}$ treatment increased COL-1A and fibronectin expressions more than alcohol with $\mathrm{CCL}_{4}$ treatment, but it was not statistically significant.

Regulation of extracellular matrix components is most important for normal vascular function, and dysregulation of protein expression such as collagen leads to detrimental pathologies such as atherosclerosis and pulmonary hypertension (Bou-Gharios et al., 2004). Connective tissue growth factor certainly has a contribution to lung fibrosis (Ponticos et al., 2009). Fibronectin has numerous functions such as cell adhesion, growth, migration, and differentiation (Pankov and Yamada, 2002). Fibronectin has profound effects on wound healing, including the remodeling and re-synthesis of the connective tissue matrix, as well as the development of granulation tissue and the formation of an appropriate matrix for cell migration and growth during tissue. Plasma fibronectin, along with fibrin, is deposited at the site of injury to stop bleeding and form a clot that protects the underlying tissue (Valenick et al., 2005).

In this study, the mechanisms of liver injury caused by alcohol, LPS, and $\mathrm{CCL}_{4}$ were investigated in terms of levels of ALT and AST, concentrations of TNF- $\alpha$, IL-1 $\beta$, and IL- 6 , and expressions of COL-1A and fibronectin.

\section{CONFLICT OF INTEREST}

No potential conflict of interest relevant to this article was reported.

\section{ACKNOWLEDGMENTS}

This work was supported by the Ministry of Education of the Republic of Korea and the National Research Foundation of Korea (NRF-2020S1A5A2A01044808).

\section{REFERENCES}

Al-Sayed E, El-Lakkany NM, Seif El-Din SH, Sabra AN, Hammam OA. Hepatoprotective and antioxidant activity of Melaleuca styphelioides on 
carbon tetrachloride-induced hepatotoxicity in mice. Pharm Biol 2014;52:1581-1590.

Bernal W, Auzinger G, Dhawan A, Wendon J. Acute liver failure. Lancet 2010;376:190-201.

Bou-Gharios G, Ponticos M, Rajkumar V, Abraham D. Extra-cellular matrix in vascular networks. Cell Prolif 2004;37:207-220.

Diehl AM. Liver disease in alcohol abusers: clinical perspective. Alcohol 2002;27:7-11.

Fleming KM, Aithal GP, Card TR, West J. All-cause mortality in people with cirrhosis compared with the general population: a populationbased cohort study. Liver Int 2012;32:79-84.

Hwang JJ, Ko IG, Jin JJ, Hwang L, Kim SH, Jeon JW, Paik SS, Chang BS, Choi CW. Combination therapy with polydeoxyribonucleotide and pirfenidone alleviates symptoms of acute respiratory distress syndrome in human lung epithelial A549 cells. Int Neurourol J 2020;24(Suppl 1): S56-64.

Jepsen P, Ott P, Andersen PK, Sorensen HT, Vilstrup H. Clinical course of alcoholic liver cirrhosis: a Danish population-based cohort study. Hepatology 2010;51:1675-1682.

Ji ES, Kim YM, Ko YJ, Baek SS. Treadmill exercise in obese maternal rats during pregnancy improves short-term memory through neurogenesis in the hippocampus of rat pups. J Exerc Rehabil 2020;16:392-397.

Kim JY, Yi ES, Lee H, Kim JS, Jee YS, Kim SE, Kim CJ, Ko IG. Swimming exercise ameliorates symptoms of MOG-induced experimental autoimmune encephalomyelitis by inhibiting inflammation and demyelination in rats. Int Neurourol J 2020;24(Suppl 1):S39-47.

Ko IG, Hwang JJ, Chang BS, Kim SH, Jin JJ, Hwang L, Kim CJ, Choi CW. Polydeoxyribonucleotide ameliorates lipopolysaccharide-induced acute lung injury via modulation of the MAPK/NF- $\kappa B$ signaling pathway in rats. Int Immunopharmacol 2020a;83:106444.

Ko IG, Jin JJ, Hwang L, Kim SH, Kim CJ, Han JH, Lee S, Kim HI, Shin HP, Jeon JW. Polydeoxyribonucleotide exerts protective effect against $\mathrm{CCl}_{4}$-induced acute liver injury through inactivation of NF-kB/MAPK signaling pathway in mice. Int J Mol Sci 2020b;21:7894.

Ko IG, Kim SE, Jin JJ, Hwang L, Ji ES, Kim CJ, Han JH, Hong IT, Kwak MS, Yoon JY, Shin HP, Jeon JW. Combination therapy with polydeoxyribonucleotide and proton pump inhibitor enhances therapeutic effectiveness for gastric ulcer in rats. Life Sci 2018;203:12-19.

Ko YJ, Ko IG. Voluntary wheel running improves spatial learning memory by suppressing inflammation and apoptosis via inactivation of nuclear factor kappa B in brain inflammation rats. Int Neurourol J 2020; 24(Suppl 2):S96-103.

Lee S, Won KY, Joo S. Protective effect of polydeoxyribonucleotide against $\mathrm{CCl}_{4}$-induced acute liver injury in mice. Int Neurourol J 2020;24(Suppl 2):S88-95.
Lee WM, Stravitz RT, Larson AM. Introduction to the revised American Association for the study of liver diseases position paper on acute liver failure 2011. Hepatology 2012;55:965-967.

Morsy B, Hamed MA, Abd-Alla HI, Aziz WM, Kamel S. Downregulation of fibrosis and inflammatory signaling pathways in rat liver via Pulicaria crispa aerial parts ethanol extract. Biomarkers 2021 Sep 7:1-9. https:// doi.org/10.1080/1354750X.2021.1970810 [Epub].

Pankov R, Yamada KM. Fibronectin at a glance. J Cell Sci 2002;115(Pt 20): 3861-3863.

Ponticos M, Holmes AM, Shi-wen X, Leoni P, Khan K, Rajkumar VS, Hoyles RK, Bou-Gharios G, Black CM, Denton CP, Abraham DJ, Leask A, Lindahl GE. Pivotal role of connective tissue growth factor in lung fibrosis: MAPK-dependent transcriptional activation of type I collagen. Arthritis Rheum 2009;60:2142-2155.

Rho JH, Ko IG, Jin JJ, Hwang L, Kim SH, Chung JY, Hwang TJ, Han JH. Polydeoxyribonucleotide ameliorates inflammation and apoptosis in Achilles tendon-injury rats. Int Neurourol J 2020;24(Suppl 2):S79-87.

Rietschel ET, Kirikae T, Schade FU, Mamat U, Schmidt G, Loppnow H, Ulmer AJ, Zähringer U, Seydel U, Di Padova F. Bacterial endotoxin: molecular relationships of structure to activity and function. FASEB J 1994;8:217-225.

Timóteo RP, Sales-Campos H, Silva MV, da Silva DAA, Da Silva Catarino J, de Sousa MAD, Júnior VR, Bittencourt ACS, Carneiro ÉM, Oliveira CJF. Pemphigus foliaceus patients (Fogo Selvagem) treated with kinesiotherapy presented lower levels of proinflammatory cytokines. J Exerc Rehabil 2019;15:460-467.

Tsai JC, Chiu CS, Chen YC, Lee MS, Hao XY, Hsieh MT, Kao CP, Peng WH. Hepatoprotective effect of Coreopsis tinctoria flowers against carbon tetrachloride-induced liver damage in mice. BMC Complement. Altern Med 2017;17:139.

Valenick LV, Hsia HC, Schwarzbauer JE. Fibronectin fragmentation promotes $\alpha 4 \beta 1$ integrin-mediated contraction of a fibrin-fibronectin provisional matrix. Exp Cell Res 2005;309:48-55.

Xie K, Yu Y, Huang Y, Zheng L, Li J, Chen H, Han H, Hou L, Gong G, Wang G. Molecular hydrogen ameliorates lipopolysaccharide-induced acute lung injury in mice through reducing inflammation and apoptosis. Shock 2012;37:548-555.

Xie L, Huang W, Li J, Chen G, Xiao Q, Zhang Y, He H, Wang Q, He J. The protective effects and mechanisms of modified Lvdou Gancao decoction on acute alcohol intoxication in mice. J Ethnopharmacol 2022;282: 114593.

Zhang DG, Zhang C, Wang JX, Wang BW, Wang H, Zhang ZH, Chen YH, Lu Y, Tao L, Wang JQ Chen X, Xu DX. Obeticholic acid protects against carbon tetrachloride-induced acute liver injury and inflammation. Toxicol Appl Pharmacol 2017;314:39-47. 